\title{
Alcohol intake and the risk of coronary heart disease in the Spanish EPIC cohort study
}

\author{
L Arriola, ${ }^{1,2}$ P Martinez-Camblor, ${ }^{1,2} \mathrm{~N}$ Larrañaga, ${ }^{1,2} \mathrm{M}$ Basterretxea, ${ }^{1,2} \mathrm{P}$ Amiano, ${ }^{1,2}$ \\ C Moreno-lribas, ${ }^{1,4,8} \mathrm{R}$ Carracedo, ${ }^{1,2}$ A Agudo, ${ }^{3} \mathrm{E}$ Ardanaz, ${ }^{1,4}$ A Barricarte, ${ }^{1,4} \mathrm{G}$ Buckland, ${ }^{3}$ \\ Lluis Cirera, ${ }^{1,5}$ M D Chirlaque ${ }^{1,5}$ C Martinez, ${ }^{1,6}$ E Molina, ${ }^{1,6}$ C Navarro, ${ }^{1,5} \mathrm{~J}$ R Quirós, ${ }^{7}$ \\ L Rodriguez, ${ }^{7}$ M J Sanchez, ${ }^{1,6}$ M J Tormo, ${ }^{1,5}$ C A González, ${ }^{3}$ M Dorronsoro ${ }^{1,2}$
}

\begin{abstract}
${ }^{1}$ CIBER Epidemiología y Salud Pública (CIBERESP), Barcelona, Spain; ${ }^{2}$ Public Health

Department of Gipuzkoa, Basque Government, San Sebastian,

Spain; ${ }^{3}$ Unit of Nutrition,

Environment and Cancer, Cancer Epidemiology Research

Programme, Catalan Institute of Oncology (ICO), Barcelona,

Spain; ${ }^{4}$ Public Health Institute of Navarra, Pamplona, Spain;

${ }^{5}$ Department of Epidemiology,

Murcia Health Council, Murcia,

Spain; ${ }^{6}$ Andalusian School of

Public Health, Granada, Spain;

${ }^{7}$ Public Health and Health

Planning Directorate, Asturias,

Spain; ${ }^{8}$ Doctoral degree

programme at UAB,

Department of Paediatrics,

Obstetrics and Gynaecology and

Preventive Medicine, Barcelona,

Spain
\end{abstract}

Correspondence to:

Mrs L Arriola, Public Health Department of Gipuzkoa, Basque Government, Av Navarra 4, San Sebastian 20003, Spain;

l-arriola@ej-gv.es

Accepted 25 August 2009 Published Online First

\section{ABSTRACT}

Background: The association between alcohol consumption and coronary heart disease (CHD) has been widely studied. Most of these studies have concluded that moderate alcohol intake reduces the risk of CHD. There are numerous discussions regarding whether this association is causal or biased. The objective of this paper is to analyse the association between alcohol intake and CHD risk in the Spanish cohort of the European Prospective Investigation into Cancer (EPIC).

Methods: Participants from the EPIC Spanish cohort were included (15 630 men and 25808 women). The median follow-up period was 10 years. Ethanol intake was calculated using a validated dietary history questionnaire. Participants with a definite CHD event were considered cases. A Cox regression model adjusted for relevant co-variables and stratified by age was produced. Separate models were carried out for men and women. Results: The crude CHD incidence rate was 300.6/ 100000 person-years for men and 47.9/100 000 personyears for women. Moderate, high and very high consumption was associated with a reduced risk of $\mathrm{CHD}$ in men: hazard ratio $0.90(95 \% \mathrm{Cl} 0.56$ to 1.44$)$ for former drinkers, 0.65 (95\% Cl 0.41 to 1.04) for low, 0.49 (95\% Cl 0.32 to 0.76$)$ for moderate, $0.46(95 \% \mathrm{Cl} 0.30$ to 0.71$)$ for high and 0.50 (95\% Cl 0.29 to 0.85$)$ for very high consumers. A negative association was found in women, with $p$ values above 0.05 in all categories.

Conclusions: Alcohol intake in men aged 29-69 years was associated with a more than $30 \%$ lower CHD incidence. This study is based on a large prospective cohort study and is free of the abstainer error.

The World Health Organization (WHO) estimates that approximately 2 billion people worldwide consume alcoholic beverages, 76.3 million of whom have diagnosable alcohol-use disorders. ${ }^{1}$ Alcohol causes 1.8 million deaths (3.2\% of total) a year and a loss of 58.3 million (4\% of total) disability-adjusted life years. In Europe alone, alcohol consumption was responsible for over 55000 deaths among young people aged between 15 and 29 years in $1999 .{ }^{1}$

Spain is the world's third largest wine producer and ninth largest beer producer. In 2003, Spain was also in sixth position in the world ranking of alcohol consumption. Alcohol use is socially well accepted and there is a general perception that certain alcoholic beverages form part of our dietary pattern. Alcohol intake, and its concomitant health and social problems, has a great impact in Spain.
Indeed, in their study of alcohol consumption patterns in the countries participating in the European Prospective Investigation into Cancer (EPIC), Sieri et $a l^{2}$ found the highest total alcohol consumption in one of the Spanish centres (San Sebastian, $41.4 \mathrm{~g} /$ day). ${ }^{1}$

Spain is one of the countries, together with China, Switzerland and France, with one of the lowest coronary heart disease (CHD) mortality rates. In Spain in 1997-8, for example, the estimated age-standardised acute myocardial infarction incidence rate for 35-64-year-old men and women was 207 and 45 per 100 000, respectively, close to the values for other southern European Mediterranean countries and much lower than the average for the WHO-MONICA study. ${ }^{3}$ Two hypotheses, namely genetic factors and environmental factors, such as the well-known Mediterranean diet, have been used to explain this phenomenon. Indeed, the moderate alcohol consumption inherent to the Mediterranean diet could somehow explain the lower rates seen in these countries.

The potential impact of alcohol consumption on CHD was first proposed in the early part of the 20 th century, ${ }^{4}$ whereas the first study to suggest an inverse association between alcohol consumption and CHD was published some 30 years ago. ${ }^{5}$ Many studies since then have confirmed this association, ${ }^{6}$ with most of them suggesting that beneficial changes in high-density lipoprotein cholesterol levels, clotting factors, insulin sensitivity and inflammation markers provide biological plausibility for the observed association. ${ }^{7}$

Despite this evidence, in 1988 Shaper et al hypothesised that a systematic misclassification error was present in most prospective studies assessing the association between alcohol use and CHD, namely the "sick quitters" hypothesis.

The characteristics of the main study variables, namely alcohol intake and CHD, differ between men and women. Women, for example, do not have the same CHD risk profile, and drinking patterns in men and women differ in terms of both the type of beverage and the quantity. The metabolism of alcohol is also different in women and men, ${ }^{10}$ therefore all these analyses have considered women and men separately.

The aim of this study is to describe the association between alcohol intake and coronary heart event risk in men and women in the Spanish cohort of EPIC. 


\section{METHODS}

\section{Study population}

The EPIC study is a multicentre prospective study conducted on half a million adult volunteers recruited between 1992 and 2000 in 10 western European countries. ${ }^{11}$ The Spanish EPIC cohort consists of 41438 volunteers enrolled in five Spanish regions, three in the north (Asturias, San Sebastian and Navarra) and two in the south (Granada and Murcia). The methodological details of the EPIC have been published previously. ${ }^{11-13}$

Participants included 15630 men and 25808 women 29-69 years of age with different social and educational levels. All participants gave their informed consent concerning the use of patient-identifiable information at recruitment. The study was approved by an ethical review board.

\section{Dietary and lifestyle questionnaires}

Information on normal food intake over the previous year was collected by means of a computerised questionnaire based on a previously validated dietary history method. ${ }^{14}$ The questionnaire was structured by meals and recorded the frequency of consumption of foods eaten at least twice a month, taking seasonal variations into account. Information on sociodemographic characteristics, lifestyle factors, including history of tobacco consumption and work and leisure time physical activity, medical history and reproductive indicators in women was collected using a lifestyle questionnaire. Both the lifestyle and computerised questionnaires were administered by a trained interviewer. Anthropometric measurements (waist and hip circumference, weight and height) were also taken at recruitment using standardised procedures. Participants were asked if a doctor had ever said they had an acute myocardial infarction, angina, thrombosis or other cerebrovascular problem, high blood pressure, hyperlipidaemia, diabetes mellitus and, for women, if they used hormone replacement therapy. The questionnaire also included a question about drug use during the past 7 days. A transformation of the national coding of baseline drugs according to the anatomical therapeutic chemical (ATC) classification ${ }^{15}$ was successfully carried out.

A follow-up telephone interview, carried out after 3 years of recruitment, was applied to $98 \%$ of the participants and included questions related to the occurrence of coronary events after recruitment.

\section{Alcohol intake measurement}

Baseline ethanol intake was calculated from the validated dietary history questionnaire. Participants reported how many standard glasses of beer and/or cider, wine, sweet liquor, distilled spirits or fortified wines they consumed per day or week during the 12 months before recruitment. Alcohol intake was calculated by multiplying the mean glass volume by the ethanol content for each type of alcoholic beverage. ${ }^{16}$ Simultaneously, information on lifetime alcohol consumption at 20,30, 40 and 50 years of age was collected during the interview. Subjects who reported an alcohol intake higher than $5 \mathrm{~g} /$ day at either 20, 30, 40 or 50 years of age but not during the 12 months before recruitment were categorised as former drinkers. Never-drinkers were defined as subjects who did not report any consumption higher than $5 \mathrm{~g} /$ day at any age and $0 \mathrm{~g} /$ day in the 12 months before recruitment. Alcohol intake was then classified in six categories for men (former drinkers, never drinkers, low intake of $0-5 \mathrm{~g} /$ day, moderate intake of 5-30 g/day, high intake of 30-90 g/day and very high intake of more than $90 \mathrm{~g} /$ day) and five categories for women (former drinkers, never drinkers, low intake of 0-5 g/day, moderate intake of 5-30 g/day and high intake of 30-90 g/day). Lifetime average alcohol intake was determined as a weighted average of intake at different ages, with weights equal to the time of individual exposure to alcohol at different ages. ${ }^{17}$

\section{Outcome assessment}

The follow-up period ran from the recruitment date to December 2004. Fatal and non-fatal coronary events were identified from the self-reported questionnaires at recruitment and at 3-year follow-up (in all centres) as well as by record linkage with three sources of information (varying by centre): hospital discharge databases (Granada had limited access), population-based myocardial infarction registries (available in Murcia, Navarra and San Sebastian) and, for the fatal events, regional and national mortality registries (National Statistical Institute, all centres) that provided information on date and cause of death were used. The link between the mortality and hospital discharges was made by reviewing the following International Classification of Disease (ICD) codes: CHD (ICD-9 410-414; ICD-10 I20-I25). A validation process was carried out to confirm and classify the coronary events identified. This validation was performed by a team of trained nurses and physicians who reviewed patient hospital medical records and medicolegal autopsy reports. The events were classified on the basis of symptoms, enzymes, electrocardiograms and biomarker findings, and possible autopsy results according to the multinational monitoring of trends and determinants in cardiovascular disease (MONICA) criteria $^{18}$ and the American Heart Association scientific statement of 2003. ${ }^{19}$ The coronary events were classified as either definite (fatal or non-fatal acute myocardial infarction or unstable angina requiring revascularisation procedures such as coronary artery bypass graft or percutaneous transluminal coronary angioplasty) or possible (fatal or non-fatal myocardial infarction in those cases that did not meet all diagnostic criteria and fatal $\mathrm{CHD}$ with insufficient information). The coronary event was considered incident if there was no indication of a recognised myocardial infarction or unstable angina requiring revascularisation procedures in the patient's records before recruitment. These latter participants were considered as prevalent CHD cases ( $\mathrm{n}=193$ ). Participants with possible acute myocardial infarctions or fatal coronary events with insufficient information ( $\mathrm{n}=119)$ were not considered as cases but were censored at the time of their coronary event.

\section{Statistical analysis}

The present study included a total of 41245 participants who were free of $\mathrm{CHD}$ at baseline. Traditional $t$ test and $\chi^{2}$ test analyses were used to compare continuous and categorised variables, respectively. The Cox proportional hazard regression was used to examine the association between alcohol consumption and CHD. Time at entry was age at baseline, exit time was age when participants were diagnosed with $\mathrm{CHD}$, died, were lost to follow-up, or were censored at the end of the follow-up period, whichever came first. The Cox model tested had "never drinkers" as the reference category and included former drinkers as a different category. The test introduced by Grambsch and Therneau $^{20}$ was used to check the proportional hazard hypothesis, stratifying by age (groups covering 5 years), which was the only variable that did not satisfy this assumption. Continuous variables are described by mean and standard deviation. Absolute and relative frequencies are given for non-continuous variables. 
Table 1 Risk characteristics at baseline for men by alcohol consumption category (including prevalent cases)

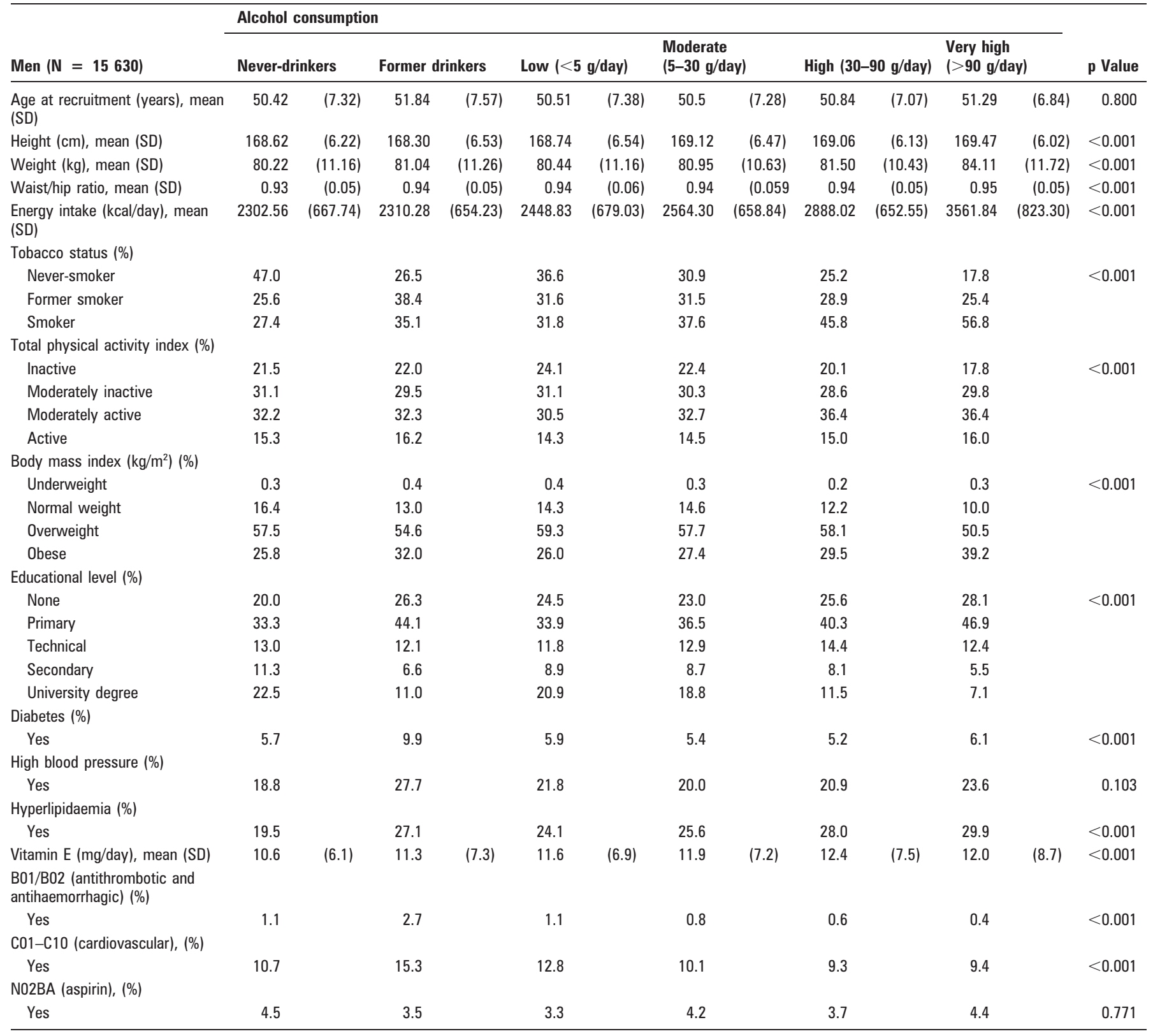

The following potential confounders were considered: centre (Asturias, Granada, Murcia, Navarra, San Sebastian), age, weight $(\mathrm{kg})$, height $(\mathrm{cm})$, waist/hip ratio, body mass index (BMI), total physical activity index (inactive, moderately inactive, moderately active, active), ${ }^{21}$ energy intake in $\mathrm{kcal} /$ day (excluding energy derived from alcohol), type of alcoholic beverage consumed, lifetime average alcohol intake, tobacco smoking status (neversmoker, former smoker and smoker), education level (none, primary, technical, secondary and university degree), vitamin E intake ( $\mathrm{mg} /$ day), use of antithrombotic and antihaemorrhagic agents (ATC code B01/B02), cardiovascular drugs (ATC code C01-C10), salicylic acid and derivatives (ATC code N02BA) and hormone replacement therapy.

To assess how high blood pressure (self-reported; yes/no), hyperlipidemia (self-reported; yes/no) and diabetes (selfreported; yes/no) might relate to alcohol in the biological pathways affecting $\mathrm{CHD}$, Cox proportional hazards models were obtained first of all for a basic model including centre, smoking status, height and education level as covariates and stratified by age. The multivariate model was further adjusted for those variables that influenced the equation (physical activity index, waist/hip ratio, vitamin E, antithrombotic and antihaemorrhagic drugs and energy intake). Each potential mediator was then added to the multivariate model to see whether the association changed. All analyses considered men and women separately. The data analysis software STATA version 10 was used for all calculations.

\section{RESULTS}

The final sample consisted of 15630 men and 25808 women. Prevalent cases ( $n=193$ ) were excluded for the Cox proportional regression, and possible acute myocardial infarctions or fatal coronary events with insufficient information ( $\mathrm{n}=119)$ were not considered cases but censored at the time of their possible event.

Tables 1 and 2 show the main descriptive statistics for the different categories of alcohol intake of the potential confounders for men and women, respectively (including prevalent 
Table 2 Risk characteristics at baseline for women by alcohol consumption category (including prevalent cases)

\begin{tabular}{|c|c|c|c|c|c|c|c|c|c|c|c|}
\hline \multirow{3}{*}{$\frac{\text { Woman }(\mathrm{N}=25 \mathbf{8 0 8})}{\text { Age at recruitment (years), mean (SD) }}$} & \multicolumn{10}{|c|}{ Alcohol consumption } & \multirow{3}{*}{$\begin{array}{l}\text { p Value } \\
<0.001\end{array}$} \\
\hline & \multicolumn{2}{|c|}{ Never-drinkers } & \multicolumn{2}{|c|}{ Former drinkers } & \multicolumn{2}{|c|}{ Low (<5 g/day) } & \multicolumn{2}{|c|}{ Moderate (5-30 g/day) } & \multicolumn{2}{|c|}{ High (>30 g/day) } & \\
\hline & 49.13 & (8.54) & 50.69 & (8.31) & 47.86 & $(8.25)$ & 47.41 & (8.11) & 47.15 & $(7.86)$ & \\
\hline Weight (kg), mean (SD) & 70.20 & $(11.90)$ & 69.41 & $(11.29)$ & 69.24 & $(11.36)$ & 67.10 & $(10.45)$ & 67.90 & $(10.31)$ & $<0.001$ \\
\hline Waist/hip ratio, mean (SD) & 0.82 & $(0.06)$ & 0.82 & $(0.06)$ & 0.82 & $(0.06)$ & 0.82 & $(0.06)$ & 0.83 & $(0.061)$ & 0.004 \\
\hline Energy intake (kcal/day), mean (SD) & 1753.59 & (525.79) & 1847.13 & $(521.30)$ & 1994.42 & $(580.48)$ & 2139.52 & (581.12) & 2413.65 & $(619.22)$ & $<0.001$ \\
\hline Former smoker & 7.7 & & 11.4 & & 10.1 & & 12.3 & & 11.7 & & \\
\hline Smoker & 15.4 & & 16.8 & & 17.4 & & 25.0 & & 32.0 & & \\
\hline \multicolumn{12}{|l|}{ Total physical activity index (\%) } \\
\hline Inactive & 3.8 & & 4.6 & & 6.1 & & 8.4 & & 8.4 & & $<0.001$ \\
\hline Moderately inactive & 13.8 & & 15.7 & & 16.0 & & 17.8 & & 18.7 & & \\
\hline Moderately active & 76.0 & & 73.0 & & 72.0 & & 67.0 & & 64.7 & & \\
\hline Overweight & 40.3 & & 45.4 & & 41.7 & & 43.5 & & 44.9 & & \\
\hline Obese & 36.6 & & 30.7 & & 31.2 & & 21.9 & & 23.5 & & \\
\hline \multicolumn{12}{|l|}{ Educational level (\%) } \\
\hline None & 40.3 & & 37.3 & & 36.9 & & 31.3 & & 25.1 & & $<0.001$ \\
\hline Primary & 42.3 & & 43.5 & & 40.2 & & 42.2 & & 46.6 & & \\
\hline Technical & 4.7 & & 5.6 & & 6.0 & & 6.7 & & 9.5 & & \\
\hline Secondary & 5.3 & & 5.6 & & 5.8 & & 6.5 & & 7.9 & & \\
\hline University degree & 7.4 & & 8.0 & & 11.0 & & 13.3 & & 10.9 & & \\
\hline \multicolumn{12}{|l|}{ Diabetes (\%) } \\
\hline Yes & 5.6 & & 6.3 & & 4.1 & & 3.1 & & 3.5 & & $<0.001$ \\
\hline \multicolumn{12}{|l|}{ High blood pressure (\%) } \\
\hline Yes & 21.8 & & 25.5 & & 19.9 & & 14.3 & & 15.2 & & $<0.001$ \\
\hline \multicolumn{12}{|l|}{ No2BA (aspirin) (\%) } \\
\hline Yes & 3.0 & & 3.9 & & 4.0 & & 4.3 & & 4.3 & & $<0.001$ \\
\hline \multicolumn{12}{|l|}{ Hormone replacement therapy (\%) } \\
\hline Yes & 5.0 & & 5.1 & & 4.8 & & 5.1 & & 5.2 & & 0.399 \\
\hline
\end{tabular}

cases). The association between alcohol and tobacco smoking is as expected for both men and women-the percentage of smokers increases with alcohol intake $(\mathrm{p}<0.001)$. The relationship between BMI and alcohol in men is linear-those who had very high alcohol consumption also had the highest percentage of obesity $(p<0.001)$-although the association was not that clear in women. Self-reported diabetes and hypertension in both men and women, and hyperlipidaemia in women only, are more

Table 3 CHD incidence rates standardised by age and smoking status

\begin{tabular}{|c|c|c|c|c|c|c|c|c|}
\hline & \multicolumn{4}{|l|}{ Men } & \multicolumn{4}{|l|}{ Women } \\
\hline & $\begin{array}{l}\text { Cohort } \\
\text { sample }\end{array}$ & $\begin{array}{l}\text { Person- } \\
\text { years }\end{array}$ & Cases & $\begin{array}{l}\text { Incidence } \\
\text { per } \\
100000\end{array}$ & $\begin{array}{l}\text { Cohort } \\
\text { sample }\end{array}$ & $\begin{array}{l}\text { Person- } \\
\text { years }\end{array}$ & Cases & $\begin{array}{l}\text { Incidence } \\
\text { per } \\
100000\end{array}$ \\
\hline Never-drinkers & 618 & 6281 & 25 & 398 & 9047 & 93048 & 52 & 56 \\
\hline Former drinkers & 1191 & 12074 & 60 & 497 & 1728 & 18185 & 16 & 88 \\
\hline Low (<5 g/day) & 2108 & 21700 & 69 & 318 & 8721 & 90131 & 38 & 42 \\
\hline Moderate (5-30 g/day) & 5103 & 52968 & 135 & 255 & 5488 & 57525 & 21 & 36 \\
\hline High (30-90 g/day) & 5502 & 57132 & 159 & 278 & 782 & 8198 & 1 & 12 \\
\hline Very high (>90 g/day) & 957 & 9869 & 33 & 334 & & & & \\
\hline Total & 15479 & 160024 & 481 & 301 & 25766 & 267088 & 128 & 48 \\
\hline
\end{tabular}

CHD, coronary heart disease. 
Table 4 Cox proportional hazard ratios (95\% Cl) for the association between alcohol consumption and CHD in men and women of the EPIC Spanish cohort for the different models tested

\begin{tabular}{|c|c|c|c|c|c|c|}
\hline & $\begin{array}{l}\text { Never- } \\
\text { drinkers }\end{array}$ & Former drinkers & Low & Moderate & High & Very high \\
\hline \multicolumn{7}{|l|}{ Men } \\
\hline Cases & 25 & 59 & 69 & 135 & 159 & 33 \\
\hline Multivariate $\dagger$ & 1.00 & $0.90(0.56$ to 1.44$)$ & 0.65 (0.41 to 1.04$)$ & $0.49(0.32$ to 0.75$)$ & $0.46(0.30$ to 0.71$)$ & $0.50(0.29$ to 0.85$)$ \\
\hline +Diabetes & 1.00 & 0.89 (0.56 to 1.42$)$ & 0.66 (0.41 to 1.04$)$ & $0.49(0.32$ to 0.76$)$ & $0.47(0.30$ to 0.72$)$ & $0.50(0.29$ to 0.85$)$ \\
\hline +Hyperlipidaemia & 1.00 & 0.85 (0.53 to 1.36$)$ & 0.65 (0.41 to 1.03$)$ & $0.47(0.31$ to 0.73$)$ & $0.44(0.29$ to 0.68$)$ & 0.47 (0.27 to 0.79$)$ \\
\hline Cases & 52 & 15 & 38 & 20 & 1 & \\
\hline Basic* & 1.00 & 1.14 (0.64 to 2.01$)$ & 0.72 (0.46 to 1.11$)$ & $0.58(0.34$ to 0.99$)$ & $0.21(0.03$ to 1.52$)$ & \\
\hline Multivariate $\dagger$ & 1.00 & 1.17 (0.66 to 2.08$)$ & 0.75 (0.48 to 1.17$)$ & 0.62 (0.36 to 1.07$)$ & 0.21 (0.03 to 1.52 ) & \\
\hline +Diabetes & 1.00 & $1.14(0.64$ to 2.02$)$ & 0.78 (0.50 to 1.22$)$ & 0.65 (0.38 to 1.12$)$ & $0.21(0.03$ to 1.51$)$ & \\
\hline +Hyperlipidaemia & 1.00 & 1.16 (0.59 to 1.91$)$ & 0.76 (0.49 to 1.19$)$ & 0.63 (0.36 to 1.08 ) & $0.20(0.03$ to 1.49$)$ & \\
\hline +High blood pressure & 1.00 & $1.12(0.63$ to 1.98$)$ & $0.73(0.47$ to 1.15$)$ & $0.64(0.37$ to 1.11$)$ & $0.21(0.03$ to 1.54$)$ & \\
\hline
\end{tabular}

*Basic: model adjusted for centre, smoking status, height and educational level and stratified by age. †Multivariate: model further adjusted by physical activity index, waist/hip ratio, vitamin $\mathrm{E}$, antithrombotic and antihaemorrhagic drugs and energy intake. CHD, coronary heart disease.

frequent in former drinkers, which supports our decision to remove them from the never-drinkers group.

At the end of follow-up 609 coronary events were included, 481 in men and 128 in women (incidence rate 300.56/100 000 person-years and 47.93/100 000 person-years, respectively; table 3). All models tested showed an inverse association between alcohol and CHD. Adding the potential mediators did not change this association, thereby suggesting that the relationship between alcohol and CHD in our study is poorly influenced by these mediators (see table 4).

In the multivariate model in men, moderate, high and very high alcohol consumption was associated with a reduced risk of CHD. The adjusted hazard ratio (HR) was 0.90 (95\% CI 0.56 to 1.44) for former drinkers, 0.65 (95\% CI 0.41 to 1.04$)$ for low consumers, 0.49 (95\% CI 0.32 to 0.75$)$ for moderate consumers, 0.46 (95\% CI 0.30 to 0.71 ) for high consumers and 0.50 (95\% CI 0.29 to 0.85 ) for very high consumers. The HR decreases in the first two categories and then remains stable for the moderate, high and very high categories (see fig 1 ).

A negative association was observed for all categories in women, although they all included unity in the 95\% CI. The adjusted HR were 1.17 (95\% CI 0.66 to 2.08), 0.75 (95\% CI 0.48 to 1.17$), 0.62$ (95\% CI 0.36 to 1.07$)$ and 0.21 (95\% CI 0.03 to 1.52) for former drinkers and low, moderate and high consumers, respectively. No cases were found among very high drinkers (see table 4).

The type of alcohol consumed did not affect the model at all (see table 5). Therefore, when considering only wine drinkers as a different category in men, moderate and high drinkers of different alcoholic beverages were at lower risk of CHD than never-drinkers and low consumers (HR 0.40; 95\% CI 0.25 to 0.64 for moderate, and HR 0.44 ; $95 \%$ CI 0.28 to 0.69 for high consumers). For "only wine drinkers" ( $\mathrm{n}=3935)$, the level of association was as follows: HR 0.91 (95\% CI 0.54 to 1.55) for moderate drinkers and 0.44 (95\% CI 0.37 to 0.97 ) for high consumers. The level of protection for moderate and high drinkers of beverages other than "only wine" was higher than for those who only drank wine.

\section{DISCUSSION}

Within the EPIC Spain cohort study, which included 609 CHD cases, we analysed the association between self-reported normal alcohol intake and CHD risk. After adjustment for potential confounders, our results suggest, as is the case with many other
Figure 1 Association between alcohol consumption and coronary heart disease in men and women of the EPIC Spanish cohort.
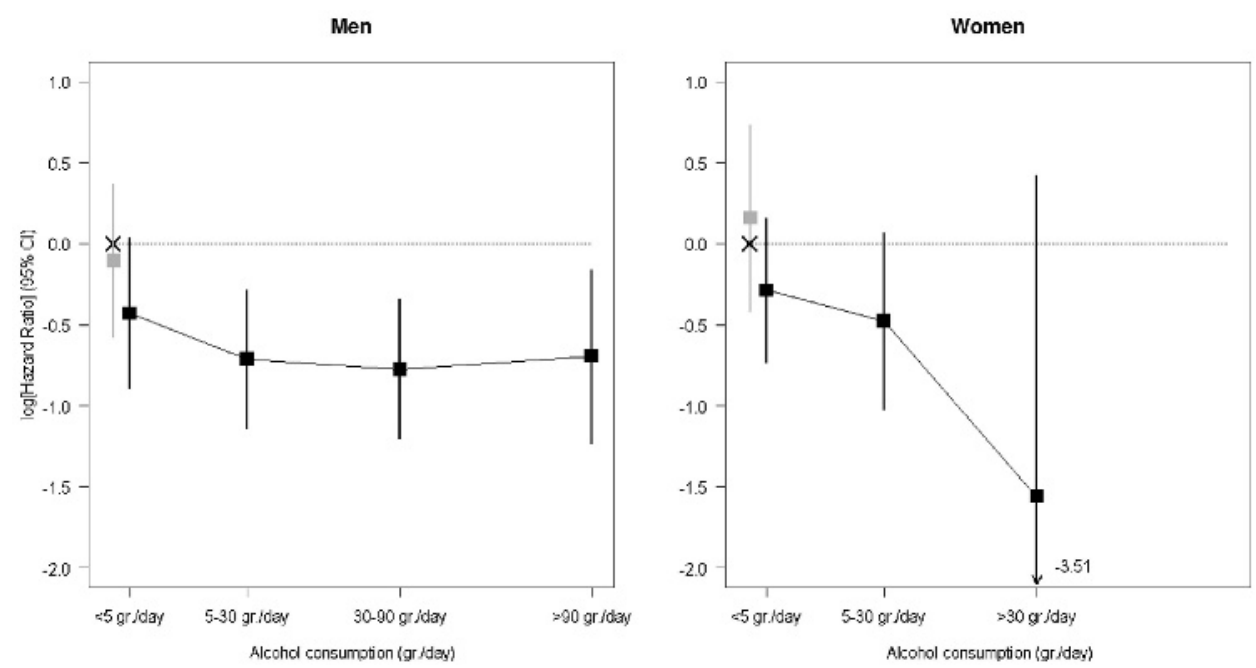
Table 5 Cox proportional hazard ratios (95\% Cl) for the association between different types of alcoholic beverage (wine, beer (including cider), fortified wines and others) and CHD in men and women of the EPIC Spanish cohort

\begin{tabular}{llllll}
\hline & \multicolumn{1}{l}{ Men } & & Women & \\
\cline { 2 - 3 } \cline { 5 - 6 } & HR $(\mathbf{9 5 \%}$ Cl) & p Value & & HR (95\% Cl) & p Value \\
\hline Wine & $0.99(0.99$ to 1.00$)$ & 0.31 & & $1.02(0.97$ to 1.08$)$ & 0.35 \\
Beer & $0.99(0.97$ to 1.01$)$ & 0.53 & & $0.94(0.80$ to 1.11$)$ & 0.50 \\
Fortified wines & $0.96(0.87$ to 1.06$)$ & 0.42 & & $0.74(0.36$ to 1.53$)$ & 0.42 \\
Others & $1.00(0.99$ to 1.02$)$ & 0.65 & & $1.06(0.99$ to 1.00$)$ & 0.28 \\
\hline
\end{tabular}

Same models as in table 4 for men and women. CHD, coronary heart disease; HR, hazard ratio.

studies, ${ }^{22-30}$ that alcohol consumption is inversely associated with CHD. However, this effect was not significant in women, probably due to the low number of CHD events in this group.

In parts of the world where CHD is not very common, and among women, in whom CHD is also uncommon, these kinds of studies show only a small or non-significant protective effect. ${ }^{31}$ Sex is an extremely potent modifier of the myocardium, ${ }^{32}$ although these differences are unlikely to be due to sex hormones alone-genetic and environmental factors probably also have some effect. The main finding in a large survey of acute coronary syndrome patients from 25 countries in Europe and the Mediterranean basin was the interaction between age and sex with respect to CHD. These differences are, however, probably due to pathophysiological variations. ${ }^{33}$ Compared with men, women's lower average volume of body water results in higher peak blood alcohol levels upon consuming a given quantity of alcohol. There are also several gender-related differences in the way alcohol is consumed that could modify the effects of biological gender differences. ${ }^{34}$

Important and significant differences in the relative risk function between genders were observed in the meta-analysis published by Corrao et $a l,{ }^{6}$ with gender significantly affecting the shape of the dose-response function.

The inverse relationship found in the study of CHD risk and alcohol consumption was similar for all types of beverages consumed. Multivariate adjustment weakened the association between CHD and wine consumption but was still significant for high levels of consumption. These findings are similar to those reported in other large prospective studies, ${ }^{35}$ which concluded that alcohol intake rather than the type of beverage consumed predicts the CHD outcome. Beverage-specific analyses are questionable as they would not have any public health relevance.

This study has several notable advantages. For example, we have separated ex-drinkers from lifelong abstainers so as to examine the potential effect alcohol has on health. The baseline characteristics of former drinkers were completely differentthey reported more hypertension, more diabetes, were slightly older and reported more consumption of antithrombotics and cardiovascular medications. The choice of reference category has often been seen as a possible bias. ${ }^{36}$ As people age and become ill or frail or increase their use of medications, their alcohol consumption decreases, with some abstaining altogether. If these people are included in the never-drinkers category, then it is not the absence of alcohol that is elevating their risk of CHD but their poorer health status. The inverse association is consistent throughout all drinking categories in our study, probably due to the absence of this abstainer error. The decrease in CHD risk begins with moderate drinking and is maintained for the high and very high categories. Fillmore et $a l^{37}$ found that J-shaped associations are more often observed for alcoholrelated outcomes in diseases dominated by prospective studies, although these studies are more likely to contain the abstainer error. Other strengths include the validity and reproducibility of the dietary history questionnaire used to assess the amount and type of alcohol consumed. The correlation between the dietary history questionnaire and the 24-h diet recalls for alcohol (g) was 0.85 in both men and women. ${ }^{37} 38$ Therefore, although recall bias in alcohol intake can lead to the misclassification of individuals, our data are probably not biased in this sense. In addition, using the lifetime average alcohol intake as a variable, the characterisation of an individual's exposure to alcohol in our study more accurately reflects that person's true long-term alcohol exposure. A further advantage is the prospective design of the study, which allows a long follow-up of a large sample of healthy individuals. There were also a reasonably large number of incident CHD cases, all of which were validated by international standards. The consistency of the results in terms of geographical similarities is also important. In a study carried out in Girona (Spain), Schroder et $a^{30}$ also found an inverse association between alcohol consumption and the risk of non-fatal myocardial infarction.

Residual or unmeasured confounding could be a limitation. ${ }^{39}$ Although we adjusted for several potential confounders in our different models, we could never be sure about the remaining confounders. Indeed, non-randomised studies are never free of residual confounding. However, any variable not considered in our model that could influence the results would have to be strongly associated with both exposure and outcome. A further limitation of our study is that some CHD patients may have been aware of early symptoms related to their disease and may have changed their alcohol consumption. Nevertheless, there were no notable differences in the results after excluding cases diagnosed during the first 2 years of follow-up.

The results of our study show a negative association between alcohol intake and CHD. This association is only statistically significant in men, probably due to the low number of CHD cases in women. We can also state, although with caution, that our study is free of the so called "abstainer error" and that residual confounding does not influence the results obtained to any significant degree.

Acknowledgements: The authors would like to thank the participants in the Spanish EPIC cohort for their contribution to this study as well as the team of trained nurses who participated in the recruitment. The authors also thank Joseba Etxeberria and Gloria Osakar from the Library of the Public Health Division of Gipuzkoa. Finally, they are grateful to the anonymous referees and the journal's editor for their comments and suggestions, which have led to significant improvements in the paper.

Funding: This work was supported by grants from the Spanish Ministry of Health (FIS PI04/0104, PI04/1644, PI04/1822, PI04/2342, PI04/2188 and PI06/0365) and CIBERESP. The EPIC study received financial support from the European Commission (agreement SO 97200302 05F02), the participating Regional Governments, the Red Temática de Investigación Cooperativa de Centros de Cáncer (RTICCC, C03/10) and the International Agency for Research on Cancer (agreement AEP/93/02)

Competing interests: None.

Ethics approval: The study was approved by an ethical review board

Patient consent: Obtained.

Provenance and peer review: Not commissioned; externally peer reviewed. 


\section{REFERENCES}

1. World Health Organization. Global status report on alcohol 2004. Geneva: WHO Library Cataloguing-in-Publication Data, 2004.

2. Sieri S, Agudo A, Kesse E, et al. Patterns of alcohol consumption in 10 European countries participating in the European Prospective Investigation into Cancer and Nutrition (EPIC) project. Public Health Nutr 2002;5:1287-96.

3. Marrugat J, Elosua R, Aldasoro E, et al. Regional variability in population acute myocardial infarction cumulative incidence and mortality rates in Spain 1997 and 1998. Eur J Epidemiol 2004;19:831-9.

4. Hill JA. In vino veritas: alcohol and heart disease. Am J Med Sci 2005;329:124-35.

5. Klatsky AL, Friedman GD, Siegelaub AB. Alcohol consumption before myocardial infarction. Results from the Kaiser-Permanente epidemiologic study of myocardial infarction. Ann Intern Med 1974;81:294-301.

6. Corrao G, Rubbiati L, Bagnardi V, et al. Alcohol and coronary heart disease: a metaanalysis. Addiction 2000;95:1505-23.

7. Rimm EB, Moats C. Alcohol and coronary heart disease. Ann Epidemiol 2007:17(5S):S3-7.

8. Shaper AG, Wannamethee G, Walker M. Alcohol and mortality in British men: explaining the U-shaped curve. Lancet 1988;2:1267-73.

9. Holmila M, Raitasalo K. Gender differences in drinking: why do they still exist? Addiction 2005;100:1763-9.

10. Mumenthaler MS, Taylor JL, O'Hara R, et al. Gender differences in moderate drinking effects. Alcohol Res Health 1999;23:55-64.

11. Riboli E, Kaaks R. The EPIC Project: rationale and study design. European Prospective Investigation into Cancer and Nutrition. Int J Epidemiol 1997:26(Suppl 1):S6-14.

12. Bingham S, Riboli E. Diet and Cancer-the European Prospective Investigation into Cancer and Nutrition. Nature Rev Cancer 2004;4:206-15.

13. Riboli E, Hunt KJ, Slimani N, et al. European Prospective Investigation into Cancer and Nutrition (EPIC): study populations and data collection. Public Health Nutr 2002; 5:1113-24.

14. Burke B. The dietary history as a tool in research. J Am Diet Assoc 1947;23:1041-6.

15. World Health Organization. ATC/DDD Index 2008 (cited 7 November 2008). http:// www.whocc.no/atcddd/indexdatabase/index.php (accessed 7 Nov 2008).

16. Slimani N, Torrent M, Farriol N, et al. European Prospective Investigation into Cancer and Nutrition (EPIC). Food composition tables. Spain: Lyon, 1991

17. Ferrari $\mathbf{P}$, Jenab $\mathrm{M}$, Norat $\mathrm{T}$, et al. Lifetime and baseline alcohol intake and risk of colon and rectal cancers in the European prospective investigation into cancer and nutrition (EPIC). Int J Cancer 2007;121:2065-72.

18. World Health Organization. The WHO MONICA project. 24 May 2006. (cited 20 November 2008). http://www.ktl.fi/monica/ (accessed 20 Nov 2008).

19. Luepker RV, Apple FS, Christenson RH, et al. Case definitions for acute coronary heart disease in epidemiology and clinical research studies: a statement from the AHA Council on Epidemiology and Prevention; AHA Statistics Committee; World Heart Federation Council on Epidemiology and Prevention; the European Society of Cardiology Working Group on Epidemiology and Prevention; Centers for Disease Control and Prevention; and the National Heart, Lung, and Blood Institute. Circulation 2003:108:2543-9.
20. Grambsch PM, Therneau TM. Proportional hazards tests and diagnostics based on weighted residuals. Biometrika 1994;81:515-26.

21. Friedenreich $\mathbf{C}$, Cust $\mathrm{A}$, Lahmann $\mathrm{PH}$, et al. Physical activity and risk of endometrial cancer: the European prospective investigation into cancer and nutrition. Int $\mathrm{J}$ Cancer 2007; 121:347-55

22. Britton A, Marmot M. Different measures of alcohol consumption and risk of coronary heart disease and all-cause mortality: 11-year follow-up of the Whitehall II Cohort Study. Addiction 2004;99:109-16.

23. Friesema IH, Zwietering PJ, Veenstra MY, et al. Alcohol intake and cardiovascular disease and mortality: the role of pre-existing disease. J Epidemiol Commun Health 2007;61:441-6.

24. Hart CL, Smith GD, Hole DJ, et al. Alcohol consumption and mortality from all causes, coronary heart disease, and stroke: results from a prospective cohort study of scottish men with 21 years of follow up. BMJ 1999;318:1725-9.

25. Klatsky AL, Armstrong MA, Friedman GD. Risk of cardiovascular mortality in alcoho drinkers, ex-drinkers and nondrinkers. Am J Cardiol 1990;66:1237-42.

26. Mukamal K. Alcohol intake and noncoronary cardiovascular diseases. Ann Epidemiol 2007:17(5 Suppl):S8-12

27. Mukamal KJ, Jensen MK, Gronbaek M, et al. Drinking frequency, mediating biomarkers, and risk of myocardial infarction in women and men. Circulation 2005;112:1406-13.

28. Mukamal KJ, Chiuve SE, Rimm EB. Alcohol consumption and risk for coronary heart disease in men with healthy lifestyles. Arch Intern Med 2006;166:2145-50.

29. Rimm EB, Giovannucci EL, Willett WC, et al. Prospective study of alcohol consumption and risk of coronary disease in men. Lancet 1991;338:464-8.

30. Schroder H, Masabeu A, Marti MJ, et al. Myocardial infarction and alcohol consumption: a population-based case-control study. Nutr Metab Cardiovasc Dis 2007:17:609-15.

31. Marmot MG. Alcohol and coronary heart disease. Int J Epidemiol 2001;30:724-9.

32. Leinwand LA. Sex is a potent modifier of the cardiovascular system. J Clin Invest 2003;112:302-7.

33. Rosengren A, Wallentin L, Gitt K, et al. Sex, age, and clinical presentation of acute coronary syndromes. Eur Heart J 2004;25:663-70.

34. Graham K, Wilsnack R, Dawson D, et al. Should alcohol consumption measures be adjusted for gender differences? Addiction 1998;93:1137-47.

35. Peele S. American Heart Association Advisory, "Wine and your heart," is not science-based. Circulation 2001;104:E73.

36. Emberson JR, Bennett DA. Effect of alcohol on risk of coronary heart disease and stroke: causality, bias, or a bit of both? Vasc Health Risk Manag 2006:2:239-49.

37. Fillmore KM, Stockwell T, Chikritzhs $T$, et al. Moderate alcohol use and reduced mortality risk: systematic error in prospective studies and new hypotheses. Ann Epidemiol 2007;17(5 Suppl):S16-23.

38. European Prospective Investigation into Cancer and Nutrition. Relative validity and reproducibility of a diet history questionnaire in Spain. II. Nutrients. EPIC Group of Spain. Int J Epidemiol 1997;26(Suppl 1):S100-9

39. Jackson R, Broad J, Connor J, et al. Alcohol and ischaemic heart disease: probably no free lunch. Lancet 2005;366:1911-12. 